\title{
Commentary: Don't sweat the compensatory sweating
}

\author{
Kimberly A. Shemanski, MD, and Anthony W. Kim, MD \\ From the Division of Thoracic Surgery, Department of Surgery, Keck School of Medicine, University of Southern \\ California, Los Angeles, Calif. \\ Disclosures: Authors have nothing to disclose with regard to commercial support. \\ Received for publication Aug 14, 2019; revisions received Aug 14, 2019; accepted for publication Aug 19, 2019. \\ Address for reprints: Anthony W. Kim, MD, Keck School of Medicine, University of Southern California, Divi- \\ sion of Thoracic Surgery, Department of Surgery, Los Angeles, CA 90033 (E-mail: anthony.kim@med.usc. \\ edu). \\ J Thorac Cardiovasc Surg 2019;158:1490-1 \\ 0022-5223/\$0.00 \\ Published by Elsevier Inc. on behalf of The American Association for Thoracic Surgery \\ https://doi.org/10.1016/j.jtcvs.2019.08.035
}

The development of compensatory sweating (CS) remains an almost unavoidable complication after endoscopic thoracic sympathectomy (ETS), occurring in $70 \%$ of patients undergoing this operation. ${ }^{1}$ Even though such a large majority of patients have CS occur after ETS, until now there have not been any true means of addressing CS surgically - other than possibly reversing the original operation, which approximately $10 \%$ of patients request. ${ }^{2}$

In this issue of the Journal, Yamamoto and Okada ${ }^{1}$ describe a novel treatment for CS that also appears to be effective and safe, possibly allowing surgeons to lower their thresholds for recommending ETS. In their study, Yamamoto and Okada ${ }^{1}$ used intraoperative laser speckle flowgraphy (LSFG) to perform precise thoracoscopic ganglionectomies. LSFG allows the monitoring of transient changes in skin blood perfusion in response to electrical stimulation of a dermatome's corresponding sympathetic nerve and ganglion. ${ }^{1}$ The evolution of this technology was tied to the principle that blood flow could be assessed from the speckled pattern of diffused light from a coherent source, such as a laser, which is also known as the laser speckle phenomenon. Its medical roots can be found in the discipline of ophthalmology, where it has been used to assess ocular blood flow. ${ }^{3}$ By translating this innovation into the discipline of thoracic surgery, Yamamoto and Okada ${ }^{1}$ reported universal success, recording $100 \%$ patient satisfaction, no mortalities, and no complications. Until this point, CS efforts have focused primarily on prevention, rather than on treatment. To some degree, this strategy has often meant avoiding ETS. Given the frequent inadequacy of conservative management of primary hyperhidrosis, the proven efficacy of ETS, ${ }^{2,4}$ and, now, the successful management of ETS's major complication, ${ }^{1}$ ETS may gain more immediate appeal.

Although some may take issue with the study's small sample size, the impressive experience of Yamamoto and Okada ${ }^{1}$ with 13,089 patients speaks to a certain level of surgical expertise that affords them an understanding of CS's nuances. The 8 patients in the cohort of Yamamoto and $\mathrm{Okada}^{1}$ who underwent surgical ganglionectomy for severe

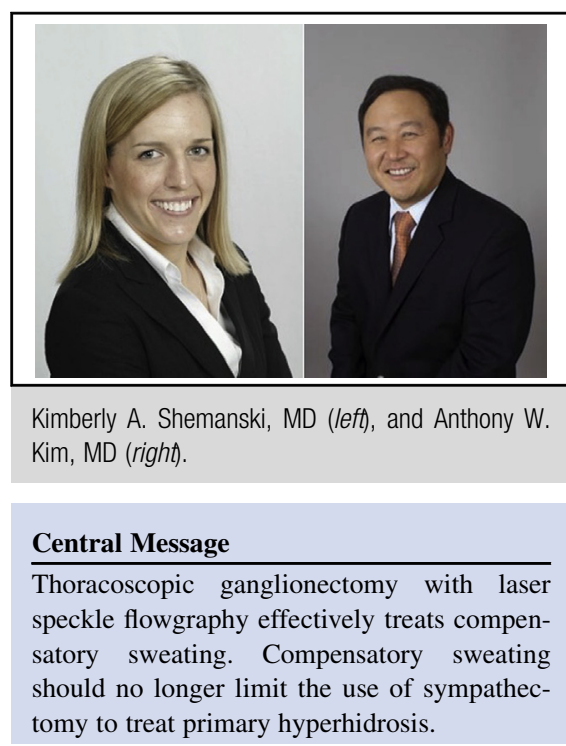

See Article page 1481.
CS represent a unique group that many thoracic surgeons would not be able to amass from their own experiences. Patients with ETS associated with severe CS form a specific cohort that expresses lower satisfaction rates with ETS. ${ }^{4}$ The vast experience of Yamamoto and Okada lends itself to bringing together a very specialized technology in LSFG, outstanding surgical acumen and technical skills, and a highly select group of patients, resulting in the opportunity to reverse a significant driver of decreased satisfaction through a meaningful intervention for this group of patients. Yamamoto and $\mathrm{Okada}^{1}$ are to be congratulated for describing an innovative and effective treatment for the vexing problem of severe CS. The possible downstream advantage of the LSFG technology in the greater context of hyperhidrosis surgery is that someday, their approach with this technology may be applicable to a larger group of patients with less severe, yet still bothersome CS or even perhaps may be used during the index hyperhidrosis operation. In fact, it is quite possible, if not probable, that Yamamoto and Okada will be "working up a sweat" in their efforts to further clinical knowledge in this area.

\section{References}

1. Yamamoto H, Okada M. The management of compensatory sweating after thoracic sympathectomy. J Thorac Cardiovasc Surg. 2019;158:1481-8.

2. Gunn TM, Davis DM, Speicher JE, Rossi NP, Parekh KR, Lynch WR, et al. Expanded level of sympathetic chain removal does not increase the incidence or severity of compensatory hyperhidrosis after endoscopic thoracic sympathectomy. J Thorac Cardiovasc Surg. 2014;148:2673-6. 
3. Sugiyama T, Araie M, Riva CE, Schmetterer L, Orgul S. Use of laser speckle flowgraphy in ocular blood flow research. Acta Ophthalmol. 2010;88:723-9.
4. Hynes CF, Seevaratnam S, Gesuwan K, Margolis M, Marshall MB. The efficacy of oral anticholinergics for sympathetic overactivity in a thoracic surgery clinic. J Thorac Cardiovasc Surg. 2016;152:565-8. 